\title{
3 Researcher collaboration complexities in participatory action research
}

\author{
Zambian experiences
}

\author{
T. Mutimukuru-Maravanyika, E. Madzudzo \\ and M. M. Songe
}

\section{Introduction}

There has been an increasing realization that agricultural and natural resource systems are complex due to interactions between socio-economic and ecological factors (Foran et al. 2014). Natural resource/agriculture managers must deal with a wide range of factors as they conduct their day-to-day activities (see Table 3.1). These multiple and complex factors and their interactions render decision making an equally complex process.

Where there are many interacting factors at play, seemingly simple events at local levels can lead to complex phenomena at the macro level. Trajectories and outcomes of such events cannot be predicted by simplistic knowledge of individual factors at lower levels (Reynolds and Holwell 2010). Consequently, in agricultural research, there has been a shift away from linear models to more holistic and systemic research approaches. The new approaches require researchers from various disciplines and other stakeholders to collaborate and work together. Such a collective initiative integrates data, techniques, tools and theories from various disciplines holistically (Barković 2010).

These holistic approaches, such as PAR, seek to change the focus of research toward the generation of actions for social change (Werkman et al. 2011; Ojha, Hall and Sulaiman 2013). A key feature of these approaches is a collaboration between researchers and natural resource-dependent local communities, aiming to help stakeholders "muddle through" complex socio-ecological systems, making deliberate and explicit attempts to embed learning into management processes and foster cooperation among those involved in managing such systems (Ojha, Hall and Sulaiman 2013). The common aim of these holistic approaches is to address challenges on the basis of insights into everyday practices that are obtained by means of participatory research.

Although these holistic approaches have been implemented over decades, many projects have remained at pilot stages - few cases exist where there has been continuous implementation in the same place with the same actors over time. Limited progress has therefore been made to demonstrate the efficacy of this approach in improving livelihoods, particularly of resource-poor farmers,

DOI: 10.4324/9781003197256-5 
Table 3.1 Examples of factors that make NRM and agricultural systems complex ${ }^{a}$

\begin{tabular}{ll}
\hline Factors at play in NRM & Examples \\
\hline Geographic & Climate \\
& Extreme weather \\
& Winds \\
& Currents \\
& Soils \\
& Governments and their willingness to address local problems \\
Political & Culture \\
Social & Social structures \\
& Religion \\
Ecological & Regeneration rates \\
& Predator-prey interactions \\
Economic & Cash needs \\
& Employment opportunities \\
& Exchange rates \\
Institutional & Markets \\
& Governance in development projects \\
Random/surprises & Tenure \\
& Disease outbreaks \\
& Earthquakes \\
& Volcanoes \\
& Economic crashes \\
\hline
\end{tabular}

Adapted from Reynolds and Holwell (2010).

${ }^{a}$ This list is not exhaustive.

and maintaining the natural resources they depend on (Allen 2001; Ojha, Hall and Sulaiman 2013). Challenges faced in implementing these approaches also include those related to the process of conducting the collaborative research itself (Smith, Syndall and Taylor 2004; Barković 2010). Hence, there is a need for new ways of dealing with these challenges (Ojha, Hall and Sulaiman 2013; Burns and Worsley 2015; Mutimukuru-Maravanyika 2010).

This chapter presents the implementation experiences of a collaborating team of researchers on one of the Consultative Group of International Agricultural Research (CGIAR) research programs, the Aquatic Agricultural Systems (AAS) Program $^{1}$ in the Barotse Floodplain in western Zambia (WorldFish Center 2011; CGIAR 2011). The team aimed to tackle a jointly identified problem using the PAR methodology (WorldFish Center 2011; Apgar and Douthwaite 2013). This chapter addresses the following questions: How does collaborative research play out in practice? What challenges arise among researchers in the process of implementing collaborative research, and how can these be addressed?

The next section presents the study site and a literature review on the challenges of collaborative research followed by a detailed description of PAR 
research methodology as used in the Zambian study. Thereafter, the chapter discusses various challenges that collaborating researchers faced as they implemented PAR and the strategies they employed to deal with these challenges. The chapter ends with a discussion and concluding remarks.

\section{The study area}

Barotse Floodplain, also known as Bulozi Plain or the Zambezi Floodplain, is located in the Western Province of Zambia (Figure 3.1). The floodplain is considered an important resource internationally, nationally and locally - it is located within the Zambezi River Basin that flows through eight countries. Although the floodplain is designated a Ramsar site and is considered to be of high conservation value, it is characterized by widespread poverty among the inhabitants (Madzudzo et al. 2013).

The floodplain has a high potential for agricultural and ecosystem services, with the lower parts of the floodplain being most suitable for crop production, especially rice (Madzudzo et al. 2013). In addition to supporting a variety of livelihood activities such as fishing, papyrus harvesting, forest product harvesting and marketing, and crop and livestock production, the floodplain provides several other functions, including supplying water for domestic use and

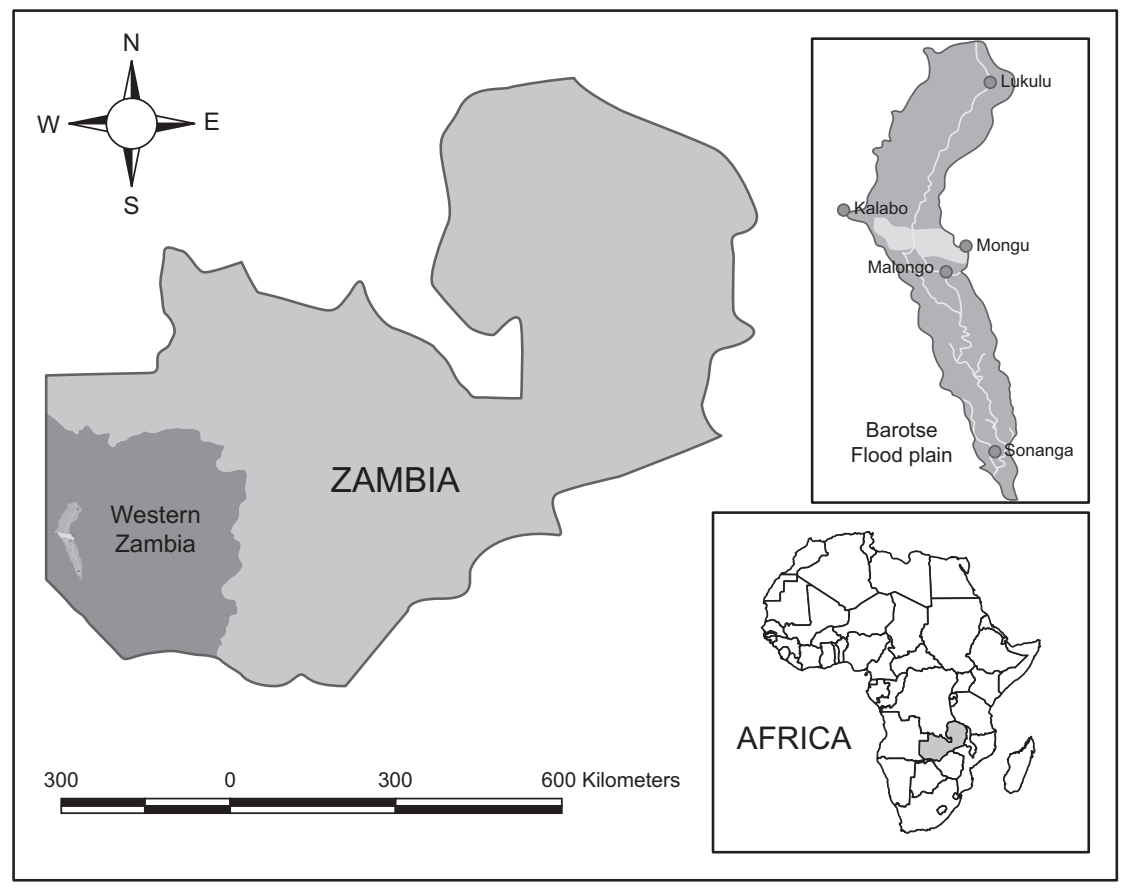

Figure 3.1 Map showing the Barotse Floodplain. 
agricultural production, and regulatory, transport and information functions. Over the years, however, the ability of the ecosystem to sustain livelihoods has been threatened, leaving communities vulnerable and heavily reliant on seasonal fishing (WorldFish Center 2007). The heavy reliance by floodplain households on a variety of natural resources makes governance and access arrangements for natural resources critical for household livelihood resilience (Madzudzo et al. 2013). Almost all households harvest grass, reeds and papyrus for house construction purposes, thatching, mat and basket production, broom making and fishing apparatus (gear) construction. Clay is also an important product that is harvested by households for use in house construction and pottery making (IUCN 2003).

The floodplain is also of cultural significance to the Lozi people who form the majority (95\%) of its inhabitants (Kazungu 2014). The tidal variations of the floodplain lead to the transhumant movement of people from the lower basin to the upper basin, and this movement is termed Kuomboka. This movement is a significant cultural event graced by the Lozi King. The Lozi traditional kingdom has been in existence for more than 400 years, including the Barotse Royal Establishment, led by a king (Litunga).

\section{Collaborative research challenges}

This section reviews the literature to highlight key challenges for collaborative research. Two distinctive categories of collaborative research can be identified in the literature: (a) disciplinary collaboration whereby collaborators identify within a single discipline but bring skills, knowledge and expertise from their own disciplines to a jointly agreed assignment; and (b) cross-disciplinary collaboration, which refers to broader interaction that spans disciplines. Crossdisciplinary research can take various forms including:

(i) multi-disciplinary collaboration, where scientists from different disciplines collaborate to address a jointly identified problem. The interpretation of results, however, is done from the perspective of one discipline that emerges as dominant in the work;

(ii) interdisciplinary research where more coordination among disciplines is required in problem formulation, analysis and interpretation. Here, collaborating researchers accept and understand and sometimes apply other disciplines' methods and approaches. Interdisciplinary research may lead to new questions and methods; and

(iii) trans-disciplinary research where research problems are jointly formulated by all and cannot fit in any single discipline. Here, collaborators accept and adapt new methods, analyses and interpretations that span several disciplines (Eigenbrode et al. 2007).

Collaborating teams of researchers, local communities and stakeholders are an anticipated essential and defining element of PAR - a key element of the 
adaptive collaborative management approach (Piggot-Irvine 2012). The PAR process that was implemented in the Barotse Floodplain is a process of collaborative systematic inquiry undertaken by participants. The research was designed to address community challenges (Greenwood and Levine 1998; Crane and Richardson 2000; Evans et al. 2014; German et al. 2012). Ideally in PAR, the difference between the researcher and the researched is blurred, as both co-generate knowledge as they undergo self-reflective cycles of planning for change, taking action and observing the process and outcomes, reflecting, learning and re-planning (Mackenzie et al. 2012; Kemmis and McTaggart 2007). In practice, as this analysis shows, the PAR process is not as sequential as outlined but fluid with some stages overlapping.

Several earlier studies (Mutimukuru-Maravanyika et al. 2016; Diaw, Aseh and Prabhu 2009; Ojha, Hall and Sulaiman 2013; Mandondo, Prabhu and Matose 2008) show that PAR has the potential to result in breakthroughs in the face of complex problems. Mutimukuru-Maravanyika was part of many of the teams that implemented PAR (or adaptive collaborative management) in several of the earlier African sites, including Mafungautsi State Forest in Zimbabwe, several communities in Central Uganda and the Anlo Beach fishing community in Ghana, in addition to the AAS Program. Madzudzo coordinated a multi-stakeholder conflict management exercise in Zambia's Lake Kariba, where PAR was being implemented in addition to the AAS Program. In this chapter, we focus on one of the challenging issues that we have experienced: how researchers from different disciplines can effectively collaborate when implementing PAR to deal with complex problems that stakeholders face. Based on the typology discussed earlier, the collaboration in the Zambian AAS case can be classified as "disciplinary collaboration" - researchers from different disciplines collectively addressed a jointly identified problem using the PAR methodology. The researchers later returned to their own disciplines for analysis and interpretation of results. At the beginning of the implementation of the project (Mutimukuru-Maravanyika and Songe joined the project a year after implementation began), collaboration among researchers was taken as a "given." As observed in similar projects (Piggot-Irvine 2012; Piggot-Irvine 2015), researchers went straight into the research process, taking a shared understanding for granted. However, it took only a short while before collaboration challenges began to emerge, such that many challenges were apparent by the time Mutimukuru-Maravanyika joined the project.

Multi-disciplinary collaboration by researchers encounters numerous difficulties. These include low prioritization and therefore lack of funding for collaboration initiatives; conflicts among researchers that arise during the collaboration; deciding on the appropriate level of integration of collaborators (Eigenbrode et al. 2007); modes of professional working, linguistic and conceptual challenges (Colfer et al. 2011; Eigenbrode et al. 2007); and collection, analysis and validation of evidence biases. Different researchers are influenced by: disciplinary research cultures (Eigenbrode et al. 2007), different ways of integrating stakeholder input into the research process, and, finally, different 
norms and perceptions of the world. Some researchers have a positivist world view, i.e., the world as something that is objectively "out there" to be investigated without researchers themselves being part of it. Others have an interpretivist view, i.e., the world as subjective - a result of human interpretation and construction (Ojha, Hall and Sulaiman 2013; Werkman et al. 2011).

Table 3.2 reflects how collaboration among researchers evolves from a superficial to an intensive level. According to Piggot-Irvine (2012), research collaborators must strive to operate at level 5, where creativity, innovation and learning operate - this is where genuine collaboration takes place. Levels 2 and 3 are important for collaborators to overcome defensive, self-protective values and strategies. This shift enables the collaboration process to move to inquiry (level 3) and eventually to trust (level 5) - in this case, trust is not a given but an outcome that emerges from complex interactions by collaborators (Piggot-Irvine 2012). There are, however, many variations in the literature on how these stages in the development of effective collaboration play out; in some cases, trust is present at the beginning but may be eroded as time goes on. Effective collaboration (level 5) requires a high degree of skill development for individuals as well as the development of dialogue and

Table 3.2 Levels of collaboration and their characteristics

\begin{tabular}{ll}
\hline Collaboration level & Characteristics \\
\hline 1 Introduction & a) Exploring commonality \\
& b) Excluding discussion of differences \\
& c) Superficial collaboration on specific tasks \\
2 Recognition of & d) No examination of defensive strategies \\
potential of self and & a) Raising awareness of differences between self and others \\
others & b) Increasing willingness to entertain multilateral \\
& c) If doubt arises, response action is mainly defensive and \\
3 Gaining an inquiry & a) Increasing empathy for others' perceptions \\
perspective & b) Genuine acceptance of validity of others' ways of \\
& c) Seeing the world through others' eyes \\
4 Transition to & a) Suspending one's known perceptions and opening up to \\
collaboration & b) True inquiry \\
5 Trust and & c) Genuine collaborative action \\
co-generation & a) New levels of awareness of our own and others' \\
& b) Inquiry leads to action \\
\hline
\end{tabular}

Adapted from Piggot-Irvine (2012). 
inquiry-based values and strategies that are associated with openness (PiggotIrvine 2015).

This section has highlighted key challenges for collaborative research. However, few examples exist that show what actually transpires among researchers and how such challenges are dealt with in practice. Our story and experiences aim to contribute to this body of knowledge as collaborative research increasingly takes center stage.

\section{Methodology}

As former members of the AAS collaborative research team, we are using the benefit of hindsight to analyze our experiences, using reflexivity to critically analyze the process we implemented from 2012 to 2016. Reflexivity involves a researcher turning the investigative lens away from others toward him or herself by explicitly examining how his or her research agenda, assumptions, beliefs and emotions influenced the outcome of the research process. Reflexivity is a critical element in qualitative research where the researcher is not a neutral bystander but an active participant in knowledge co-production (Gluck and Daphne 1991; Hammersley and Artinson 1995) and dissemination. Reflexivity requires researchers to question and examine their preconceived ideas and perceptions. This poses challenges as sometimes researchers feel threatened by exposing their positions and experiences (Borochowitz 2005) in confessionlike-reflexive accounts. This challenge is not unique as other scholars point out that it becomes easier to be more reflexive with time, distance and detachment from the research process itself (Mauthner and Doucet 2003). In our case, we are privileged to be writing this account four years after the project came to an end - at least regarding the outside intervention.

It is also important to understand the background regarding connections among the PAR practitioners. This is valuable in helping us demonstrate the difference between the ideal and real inter-organizational and intrateam dynamics. The team comprised two tiers: researchers and field officers. The former comprised about 20 researchers from four international agricultural research institutions - Bioversity, WorldFish, the International Water Management Institute (IWMI) and the International Livestock Research Institute (ILRI) - with different experiences in natural resource management. Researchers from WorldFish and ILRI were based in Lusaka, Zambia, while those from Bioversity and IWMI, were based outside Zambia, regularly visiting to conduct and follow up on research in the Barotse Floodplain. Some of the researchers responsible for leading different components of the program such as PAR, value chain research and gender transformative research were based in Lusaka, others were based outside of Zambia. The latter tier, field officers (dubbed the hub team), was responsible for implementing field activities with support from the researchers who were based in the Barotse Floodplain, $600 \mathrm{~km}$ from Lusaka. A hub manager coordinated the work of field officers and oversaw the implementation of all field activities. A regional 
coordinator had oversight of the researchers in Lusaka. The researchers were required to liaise and communicate with the hub manager before going to the field. All Barotse researchers were being supervised by global AAS researchers based in the different headquarters where the different participating institutions were based - for example, for WorldFish, the global researchers were based in Penang, Malaysia. The linkages between the researchers in Lusaka and their global offices as well as the field are shown in Figure 3.2. The figure shows what was supposed to happen ideally, but in reality, the linkages were more

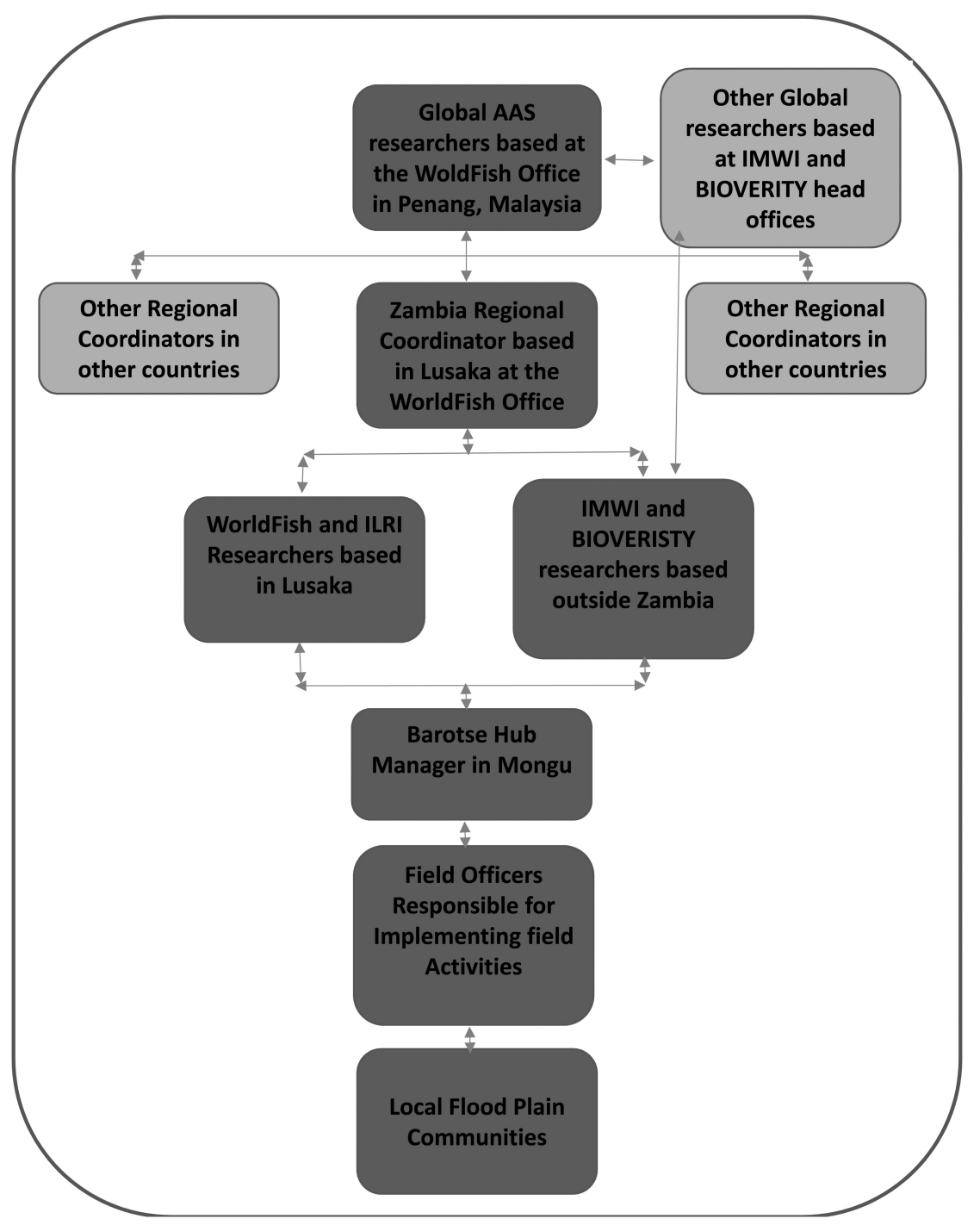

Figure 3.2 Expected linkages between the global, Lusaka and Barotse Hub researchers. 
complex, with researchers in Lusaka communicating directly with their head office supervisors and also directly with the field officers without engaging the hub manager, resulting in many tensions as managers felt their authority was not being respected. Issues of authority, power and influence were inherent to the project and sometimes had nothing to do with the program's intended outcomes.

In this research, process documentation was done by various stakeholders including researchers, local community facilitators and local partners who were engaged in the research activities. Here, we analyze both the data collected through process documentation (including community reflections) and also our own personal documentation, experiences and observations. Most of the data we collected was qualitative in nature and we used content analysis, a qualitative method for analyzing data and interpreting its meaning. We now turn to a discussion of our PAR experience in greater detail with analysis.

\section{An overview of the Barotse Floodplain PAR process}

In this section, we retell the story of how PAR was implemented in Barotse, paying attention to elements of the story that are directly related to the focus of the study. PAR processes were implemented using the learning by doing approach and stakeholders learned and improved over time as the story will show.

\section{Understanding the context}

Following global AAS procedures, several context studies were intended to be conducted at the start of the program. These included diagnostic studies governance, agro-biodiversity, flood risk and ecosystem assessments - and gender studies (though some were conducted much later in the program). These studies aimed to generate understanding about resource governance, local community nutrition status and community gender dynamics. At these early stages, the implementation of these studies was less coordinated, and the studies were conducted separately by various researchers with limited interactions with each other. Because of this limited coordination, researchers sometimes collected similar information from the same communities, leading to community research fatigue. After about a year of studies, community members began to ask questions like, "when will research stop and development work begin?" Community members, perhaps because of their previous experiences with other "donors" who delivered assistance, were becoming impatient and wanted to get tangible benefits from the project. This quickly became a thorny issue that was later discussed at several platforms. For instance, during a theory of change workshop organized in June 2014 at Senanga Safaris in Barotse, the same question arose and there were varied responses from researchers present. Some expressed the opinion that the tangible benefits were at that time limited because of the few development partners engaged by the project, while others 
felt that tangible benefits would eventually be realized when implementation began after understanding the context. These varied understandings of how development was to come about brought frustrations to both the researchers and program stakeholders, including community members.

When conducting these studies, researchers were unclear about how their studies were related. They were conducted individually in silos - mostly pursuing individual goals and objectives. Some researchers were unhappy when asked to collect data for others as discussion with one researcher revealed.

After I sent my draft questionnaire to AAS team members for their inputs, I realized some people wanted me to collect additional data on their behalf... and they got angry when I refused to add their own questions. Doing these initial surveys cost a lot of money mainly because I was not based in Zambia and I decided to work with highly skilled and expensive researchers from the University of Zambia. Adding the extra data from other team members would make my survey too long, too expensive and it would probably cause research fatigue among farmers.

Two years into implementation of the program (from 2011 to 2013), many researchers still had not understood why they were supposed to collaborate with others - and the situation was the same for those who joined the program later. The following story from a researcher working for one of the CGIAR centers illustrates this point (Box 3.1).

\section{BOX 3.1 A STORY THAT SHOWS A LACK OF UNDERSTANDING BY RESEARCHERS OF REASONS TO COLLABORATE}

Since I was coming from a completely different world of animal health and my institution was neither coordinating nor directly implementing the AAS program, it became very difficult for me to understand why I was supposed to "waste my time" participating in joint planning activities with AAS researchers who were mostly from a social sciences background. I initially felt that the PAR expert was being pushy and domineering as she asked me for my activity reports, which I would have shared with my boss at our head office in Nairobi. For me, I thought that I had to interact with these people just because I was being hosted by WorldFish as our institution had no physical presence in Zambia. At first, I saw no value in investing so much time in other researchers' activities given the fact that I had my own individual obligations to fulfill toward my employer and these were clearly spelled out. 
However, my point of view changed drastically for the better after I was invited to, and attended a PAR workshop where, simply by interacting with fellow researchers as well as stakeholders in a relaxed setting, I came to appreciate the wonderful synergies that existed between the initiative I was leading and the others such as productivity, value chains, knowledge sharing and learning, to mention just a few. I later was able to realize that my research was also going to take place in the exact same place, the Barotse Floodplain and it would be easier to make prudent use of all available resources. Collaborating with other researchers would therefore afford everyone the leverage to collect data "on one trip" in the same vehicle and interacting with the communities all at the same time.

The studies were also conducted without a prior understanding of how the collected data would be shared among researchers after collection, considering that these researchers were coming from different institutions. For instance, when asked to share his data, one researcher from a CGIAR lead partner wanted to confirm the data-sharing policy with his institution first. This resulted in huge delays before data sharing could be done and by the time it was shared, many of the researchers had already gone ahead and duplicated the data gathering process, thereby further tiring the community and wasting program resources.

\section{Developing shared visions and planning the collaborative research process}

Following the same global AAS processes, in August 2012, representatives of all stakeholders convened a workshop to create a vision for their joint work in the hub. ${ }^{2}$ Using the diagnostic studies and through their own visioning process, they defined potential areas for research intervention and devised a development challenge dubbed the hub development challenge ${ }^{3}$ (CGIAR Research Program Aquatic Agricultural System 2012) to be tackled through PAR initiatives:

To make effective use of the seasonal flooding and natural resources in the Barotse Floodplain system through more productive and diversified aquatic agricultural management practices and technologies that improve the lives and livelihoods of the poor.

Engagement in selected communities through PAR commenced during the planning phase starting with visioning and action planning. Several meetings were organized to help community members in the villages build a "community dream" (Wollenberg et al. 2000; Evans et al. 2006). In addition to articulating their dreams, community members then developed action plans to 
Table 3.3 Summary of dreams from the communities

Emerging themes identified as a priority by communities ${ }^{4}$

1. Improved farming practices and diversification

2. Canal management

3. Livestock management and diversification

4. Sustainable management of fisheries

5. Improved water and sanitation

6. Natural resource management

7. Food processing and post-harvest handling

8. Access to markets

9. Improved gender relations

a These were later synthesized by the facilitators and other key stakeholders. In their visions, communities identified various desires, including schools, tarred roads, hotels, airports, better houses, food security and so on. Many of their desires fell outside the agricultural scope that was the focus of the project. Non-agricultural activities were therefore dropped, and only agricultural related ones were picked up and synthesized. The team paid attention to gender, age and so on when communities were developing their visions.

address the salient challenges they faced. The action plans were developed to harness the opportunities and local strengths so as to realize their dream for the next five years. Table 3.3 provides a synthesis of community dreams that action plans focused on in order of their importance. In developing their dreams as well as coming up with the action plans, facilitators made sure that all views of different gender groups as well as age groups were captured.

After development of the community-level plans, the research program of work was developed by all stakeholders in a strategic design workshop. The community representatives, researchers and other stakeholders were brought together to identify a number of research interventions that would enable collective tackling of the hub development challenge. Although these research interventions were at a higher (hub) level, community differentiated responses were implemented in response to specific issues raised in each community. The research initiatives that stakeholders agreed on included: value chains, flood risk management, gender transformation and productivity and each one was led by a researcher. The focus of these initiatives evolved and transformed over time through reflection and learning processes at both community and hub levels. It is important to note that there was some worry among the researchers as some community aspirations were not agriculture related - these were kept on the list for a while to avoid demoralizing the communities but were later offloaded to relevant institutions that were best placed to address them.

\section{Implementing research initiatives in Barotse}

After the program planning phase outlined earlier, researchers leading different initiatives were asked to develop individual action plans for their initiatives and 
these formed the individual performance management goals. The researchers' supervisor would then approve the initiatives before implementation and the individual performance goals were the basis of researchers' evaluation at the end of the year. Although the research was being done jointly through the PAR methodology, each researcher was to be evaluated on the basis of his or her own performance goals. The results of this evaluation determined the fate of the researcher at the end of the year - whether or not the researcher continued to be employed by her/his organization. Obtaining an unsatisfactory grade for two consecutive years would lead to the termination of employment. This individual performance evaluation system complicated the implementation of the collaborative research work, as individuals were under pressure to implement activities according to their individual performance goals; this resulted in many researchers working in silos. Some, because of the pressure to perform, used different approaches to convince stakeholders to participate in their work, thereby contradicting the participatory nature of the program. For instance, some paid large sums of money to AAS Program partners as part of their travel and subsistence $(\mathrm{T} \& \mathrm{~S})$ allowance to lure them to participate. Although all AAS staff were paid T\&S allowances when implementing activities in the field, the T\&S amount for program implementing partners was not fixed and varied depending on the researchers and the funding they had for their research initiatives. This created unhealthy competition among researchers as some partners refused to work with those who paid less T\&S, even though they were part of the same program.

Working with and through partners was one of the critical issues that was strongly emphasized to researchers at the beginning of the AAS Program; researchers were made to understand that this was a pre-condition for sustaining research outcomes. How this was to translate into practice, however, remained unclear at the beginning of the program and researchers made all sorts of arrangements with partners as they were rushing to implement their activities. Some researchers established contact with the program partners directly while others did this through the field or hub office in Mongu. Sidelining the hub office, it later turned out, did not go well with the hub manager as she felt that her authority was being undermined.

As mentioned previously, the program was supposed to be implemented using the PAR approach and it was assumed that the researchers who were hired knew what the approach was about and how to implement it in practice. It however became apparent two years later that this assumption was wrong, as one scientist pointed out:

When I joined the program there was no discussion about what the Research in Development Approach (RinD, whose key element was PAR) was. It was assumed that everyone was well equipped to implement the approach. My colleagues and I, for instance, were aware of the research for development approach that the Livestock and Fish CRP was using as we had links with it. We therefore decided to use this approach to 
design our work as to us this was participatory action research. We however were later informed by the AAS Program Coordinator that the RinD approach involved engaging with various stakeholders at every stage. We therefore set up a stakeholder group, but we were initially not sure of what was supposed to be done with the group. The group later evolved into a sounding board and later still, an innovation platform.

\section{Learning lessons and adapting}

Reflection and learning workshops were part of the explicit PAR design to support teams and took place regularly. We tackled many contentious issues in such workshops. The first was a three-day event in November 2013 at Senanga Safaris (Mutimukuru-Maravanyika et al. 2013), attended by 19 men and eight women, including staff from the CGIAR collaborating centers. The workshop objectives were to: reflect on the progress made through the implementation of the various components of the program; consolidate learning from implementation; further develop the hub theory of change; and use lessons learned to contribute to 2014 planning. At this meeting, all stakeholders, including the researchers, had an opportunity to share their work, challenges and outputs and learn from each other. Participants of the workshop agreed that there was a need to:

- improve linkages between the different components of the program;

- build capacity for all stakeholders on what PAR was;

- $\quad$ put in place effective communication platforms;

- $\quad$ rethink data sharing and management systems;

- improve collaboration and joint planning so as to reduce community research fatigue; and

- revisit the way researchers engaged local communities and program implementing partners.

Implementing PAR activities, including reflection and learning platforms, however, was not easy and many conflicts arose among the AAS researchers during such workshops. An example of such a conflict is presented in Box 3.2.

\section{BOX 3.2 RESEARCHER CONFLICT DUE TO DIFFERENT BACKGROUNDS}

When the first reflection and learning workshop was organized in November 2013 (Mutimukuru-Maravanyika et al. 2013), two researchers with different backgrounds (one was African and had experience facilitating workshops in Africa, while the other was European and had 
experience facilitating workshops in Latin America) were tasked to lead the activity. When discussing the finer details of the workshop program, a conflict erupted. The African researcher suggested including an item on workshop rules and the European researcher was uncomfortable with this, saying that including this item would seem as if workshop participants were being treated as little children.

The African researcher, who eventually facilitated the workshop, decided to include the workshop rules on the agenda. It later turned out that the workshop rules were extremely useful. The workshop participants had a tendency to move in and out of the workshop as and when they wished, had their telephones continuously ringing loudly, thereby disrupting the proceedings, and many were not punctual. The developed workshop rules helped to stop all these disruptive behaviors as workshop participants came up with stiff punishments for those who did not observe the workshop rules. Two of the culprits who were punished for breaking the workshop rules were members of the Barotse Royal Establishment, locally known as Indunas. Indunas were known to always come late for meetings, and no one could question them as they were highly respected in Barotse. The African researcher, probably because she was a foreigner in Zambia, was not hesitant to enforce the rules when the Indunas were late for the workshop - they never came late again after that. At the end of the workshop, the two researchers agreed that the rules helped to bring order in the workshop, and later they became a part of all subsequent workshops.

Conflicts, as the Barotse case shows, were part and parcel of the entire PAR implementation, making the process complex and difficult. For various reasons, including differences in backgrounds, power, gender, beliefs and values, researchers formed "clubs or cartels" whose members would support each other and fight against members of different clubs when the opportunity availed itself. Rivalry among researchers became the order of the day, especially during the early stages of the research process, with researchers sometimes arguing and embarrassing each other in the presence of other stakeholders (e.g., AAS partners). In one such example, two researchers had a heated exchange of words during a PAR learning and reflection workshop where all stakeholders, including partner organizations and local community representatives, were present. The two researchers exchanged unkind words while everyone was listening. Possible reasons such an incident occurred include hidden personal conflicts that were not surfaced and a general lack of communication.

Following the lessons learned from the reflection and learning workshops, we instituted several strategies to address the challenges we faced. Some of the strategies are discussed separately below. 
Joint planning and implementation of research initiatives

We organized face-to-face meetings to enable researchers and all stakeholders to share planned activities, learn and give each other feedback, develop an integrated plan of work and agree on implementation that would avoid duplication and reduce community research fatigue. Several of these planning workshops were organized and began with researchers sharing and agreeing on team objectives and outcomes that were to be realized each year. After developing the team objectives and plans for the hub, individual researchers then developed their individual work plans for the year. This ensured that individual work contributed to the overall hub objectives. Such workshops became important in facilitating a convergence of stakeholders' and researchers' views.

We began jointly planning the different research initiatives to address the challenges of researchers working in silos. Joint planning workshops aimed to nurture researcher synergies and ensure that PAR activities were jointly executed - they led to the development of a hub plan of work that clearly indicated activities to be implemented each month and by whom. From these workshops, researchers then started implementing their activities jointly and in a coordinated manner. With joint planning of activities, communication and relations among the researchers improved - moving from adversaries to genuine collaborators with an increased understanding of the program and how the different pieces of work were all linked up.

\section{Team building}

We hired external facilitators to lead several team-building activities for all researchers (Mutimukuru-Maravanyika and Mwiya 2014). Such activities included retreats that were organized for stakeholders, including the researchers, to encourage joint learning from each other's work. In the team-building activities, researchers had opportunities to give and receive feedback as well as develop team visions and action plans. Researchers extracted their individual action plans from the team action plan, and this helped to deal with the challenge of divergent individual performance goals and team goals. Such team-building activities were part and parcel of the PAR process and they contributed immensely to making collaboration by researchers possible and effective.

\section{Generating a shared understanding of $P A R$}

In line with global AAS capacity development processes, we conducted PAR self-assessments for all stakeholders, including the researchers, in Barotse in 2014 (Mutimukuru-Maravanyika and Apgar 2014; Mutimukuru-Maravanyika et al. 2014). The assessment process, which focused on understanding the core PAR competencies, involved a number of parallel steps designed to enable the engagement of the different sub-teams and to build on and fit into ongoing 
activities in the hub. The process included rapid assessments by AAS researchers, partners and community facilitation teams and culminated in a self-assessment workshop in June 2014. During the workshop, team members assessed their own capacities and prioritized key areas for capacity development interventions. Capacity development activities were later implemented, and these included a mixture of training workshops, on-the-job support and peer learning opportunities.

\section{Transforming partnership engagement approaches}

To tackle the issue of ad hoc approaches for engaging the program partners, stakeholders discussed and agreed on operating standards, for instance, setting a fixed $T \& S$ rate to be offered by the program. In addition, rather than engaging different partners individually, the program decided to develop memoranda of understanding (MOUs) for all partners, taking into account activities for all research initiatives. This standardization of practice helped in reducing confusion and smoothed implementation of activities by partners.

\section{Putting in place a communication system}

Due to the need for improved communication, researchers (together with other stakeholders) agreed on a number of strategies. These included: developing and sharing a comprehensive list of all stakeholders with their contact numbers; developing monthly bulletins to be shared with all stakeholders highlighting the work conducted, key successes and challenges; ${ }^{4}$ and organizing various face-to-face meetings, including seminars where researchers got opportunities to present their work and receive feedback from the rest of the team.

As time went by, the team of researchers transformed from adversaries to improved collaborators. The transformation was phenomenal and required one to change one's mindset and accommodate others. Many researchers formed strong coalitions that have continued to exist up to now, several years after the program ended. Although researcher collaboration had improved remarkably, with the potential of positive influence on the PAR outcomes going forward, the AAS Program was evaluated four years into implementation and donors were not happy with the outcomes that had been realized by that time. The donors immediately withdrew their support and the program ended.

\section{Discussion}

In this chapter, we explored the question of how to manage research challenges associated with interdisciplinary teams. We illustrated these interorganizational dynamics by critically reflecting on our own experience of working together in the Barotse Floodplain of Zambia. Specifically, we sought to address the following questions: How does collaborative research play out in practice? What challenges arise among researchers in the process 
of implementing collaborative research and how can these be addressed? We synthesize our findings here.

Collaborative research becomes a meeting point of different actors from different backgrounds and professional cultures. The Barotse collaborative research experience outlined here clearly shows that effective collaboration among researchers implementing PAR is not spontaneous but is an emergent property of deliberate and conscious efforts by the participants. PAR implementers should not assume that the researchers constituting the implementation team are a homogenous group - rather, they are different and bring along "baggage" that has a bearing on how PAR plays out in practice. In addition, the situation is worsened by individual survivalist strategies that can undercut the team approach required in implementing PAR.

\section{Balancing individual performance agreements and collaborating with others}

As we saw previously, performance management systems are critical in either enhancing or discouraging collaboration among researchers. Performance management systems that promote collaboration, with the benefit of hindsight, are those that link individual performance with team performance goals - as happened later in the AAS Program. Managers of collaborating researchers must not reinvent the wheel but use well-developed management approaches such as management by objectives (MBO) (Drucker and Maciariello 2008). When using $\mathrm{MBO}$, managers realize that each member of an organization contributes something different. But all members must contribute toward a common goal with their efforts pulling in the same direction and fitting together to produce a whole. $\mathrm{MBO}$ ensures that every job in the endeavor is directed toward the objectives of the whole organization. MBO however, does not happen automatically but should be purposefully organized and be made the living law in managing researcher collaborative efforts.

Effective leadership and strategies that promote collaboration among researchers and partners in PAR processes are therefore critical (Barković 2010; Schultz and McIntyre 2019). Leadership is important in creating supportive performance management systems, creating opportunities for joint planning and implementation and ensuring that communication systems are in place. Effective leadership promotes transparency and democracy, creates conducive environments for researchers to communicate, develop trust and collaborate effectively. Short of this, we have shown that performance management systems can promote perverse habits that threaten the positive intentions of development programs.

\section{Lack of coordination and understanding of how one's work contributes to broader program objectives}

"Learning as you go" can be misconstrued as radar-less muddling through. When researchers were collecting data in silos and were opposed to 
collaboration in data collection, multiple researchers ended up collecting the same data, wasting resources and contributing to community research fatigue. Here, the MBO approach could have helped researchers to jointly plan and implement their work as well as see how their work contributed to the broader program goals. With coordination, all studies could have been conducted swiftly, and PAR activities could have been implemented in a timely fashion to avoid the research fatigue that was experienced in the Barotse. If the PAR activities had been implemented earlier, more outcomes would likely have been realized and this could have prevented the premature program closure by donors.

\section{Lack of data-sharing mechanisms}

The issue of data sharing, as seen from Barotse, is critical in collaborative research - lack of clarity on data-sharing mechanisms resulted in different researchers closely following their institutional policies, which did not mesh well with the collaborative nature of this research. Given that all research was being funded by the same program, issues of data ownership and how it would be shared among researchers should have been discussed at the outset. Leaving the issue to be resolved in a learning by doing fashion, as happened in Barotse, was a big mistake, which could have been avoided, thereby saving precious financial resources.

\section{Researcher conflicts}

Conflicts, such as those experienced in Barotse, are inherent to researcher collaboration efforts. Those intending to engage in collaborative research must, from the onset, think about ways of reducing and managing these conflicts. Putting in place effective communication systems is critical for reducing and managing such conflicts. For instance, the combative exchanges between researchers while in the company of stakeholders could have been avoided, since the two researchers were based at the same office. Had communication lines been clear, they could have discussed and resolved their issues privately at the office. Such unhealthy relationships among the researchers themselves stalled progress and worked against the collaborative nature of the program.

\section{Misunderstandings about PAR leading to conflicting approaches}

Rather than assuming that researchers know what PAR is in collaborative research, all researchers need to undergo capacity development on PAR processes. When this happens, the situation of discovering that researchers have different perceptions of PAR years after implementation will be avoided. Colfer et al. (2011) in CIFOR's Landscape Mosaics project made similar observations. The project leader and the ACM coordinator spoke different languages about ACM, and it took a long time for the two to discover this miscommunication. 
With the benefit of hindsight, PAR capacity development for all collaborators must be given high priority in PAR collaborative work (Colfer et al. 2011); see also Chapter 6, this volume). It is important however, not to take such a capacity development program as a one-off activity, but recurrent processes are needed where researchers continue to learn and improve. Such capacity development activities must also be part of all onboarding programs for new staff who join PAR programs.

In addition, many researchers have no previous experience conducting collaborative research. Such researchers need to gain the related skills and should be supported in their learning process. This learning process happens at an individual level as one gets an opportunity to reflect on one's own values, perceptions and beliefs after interacting with others (see also Eigenbrode et al. 2007). This transformation takes place speedily when there is transparency and when opportunities exist to surface and deal with existing conflicts. The more the researchers dialogue and discuss and resolve existing conflicts, the more they will learn from each other and understand why different views and perceptions exist. Although the process takes a considerable amount of time as other scholars have pointed out (Hattori and Lapidus 2004; Piggot-Irvine 2012), without this investment, implementing PAR will be hampered by collaborative challenges among the researchers themselves.

\section{Concluding remarks}

Fostering effective collaboration among researchers should be given a high priority in any effort to implement PAR. An effectively collaborating research team has a high chance of success as confusion, duplication and contradictions are reduced. The Barotse case has shown that collaboration by researchers in PAR processes is not automatic and should not be taken for granted. This is because researcher interactions are filled with challenges that can threaten outcomes of joint work. Doing PAR research in collaborative teams requires a conscious effort by researchers to move from superficial to genuine collaboration. This movement is possible when: effective leadership and supportive performance evaluation systems are in place; conflict resolution mechanisms and effective communication systems function well; researchers gain essential collaboration skills; capacity development activities are organized to ensure a shared understanding of the research process and methodologies to employ; and finally, data-sharing mechanisms are agreed upon at the onset of collaborative research programs.

This chapter examined the process of fostering genuine collaboration among research teams. It has shown that collaboration requires investments in time and financial resources as well as critical personnel to steer the process from the beginning. There is, however, a challenge as such resources are usually not budgeted for at project planning stage; collaboration by PAR researchers is often assumed to already exist. Without nurturing its emergence among collaborative research team members, PAR efforts may fail to realize their potential. 


\section{Acknowledgments}

We would like to thank the CGIAR Fund Council (and its numerous donors) for funding the AAS Research Program - of which this research was part. We are also grateful to Dr. L. Chapungu from Great Zimbabwe University in Zimbabwe for generating the map of the Barotse Floodplain and to the two anonymous reviewers who provided invaluable critique.

\section{Notes}

1 The AAS research program was coordinated by WorldFish and implemented by two other CGIAR centers, Bioversity and the International Water Management Institute. It focused on harnessing the potential of aquatic agricultural systems including inland floodplains, major river deltas and coastal environments to lift people out of poverty. The program was implemented in five countries - dubbed AAS hubs, including the one in Zambia in the Barotse Floodplain System as an exemplar of African inland floodplains. The program was implemented for about three years but was abruptly closed down for various reasons, including a change in donor priorities.

2 Each of the selected countries where AAS was implemented was dubbed a "hub."

3 The challenge was phrased positively showing what stakeholders desired to see when all problems of the hub were addressed. At the time of developing the challenge, there was ineffective use of seasonal flooding with poor agricultural productivity and poor natural resource management (including fisheries).

4 These were similar to ACM Zim News, a learning and sharing platform for forest extension officers involved in the program, published by the Mafungautsi ACM project (Mutimukuru and Kozanayi 2005; Maravanyika and Kozanayi 2006a, b). In the early 2000s, the Bogor-based ACM team also published ACM News, a publication with similar goals, including articles from all the 11 original ACM sites.

\section{References}

Allen, W. J. 2001. "Working Together for Environmental Management: The Role of Information Sharing and Collaborative Learning." $\mathrm{PhD}$ (Development Studies). New Zealand: Massey University.

Apgar, M., and B. Douthwaite. 2013. Participatory Action Research in the CGIAR Research Program on Aquatic Agricultural Systems. Program Brief: AAS-2013-27. Penang, Malaysia: WorldFish Center.

Barković, D. 2010. "Challenges of Interdisciplinary Research.” Interdisciplinary Management Research 6: 951-60.

Borochowitz, Dalit Y. 2005. "Teaching a Qualitative Research Seminar on Sensitive Issues." Qualitative Social Work: Research and Practice 4 (3):347-62.

Burns, Danny, and Stuart Worsley. 2015. Navigating Complexity in International Development: Facilitating Sustainable Change at Scale. Edited by D. Burns. Rugby, UK: Practical Action Publishing.

Consultative Group on International Agricultural Research (CGIAR). 2011. CGIAR Research Program Aquatic Agricultural Systems Program Proposal. Penang, Malaysia: WorldFish Center.

CGIAR Research Program Aquatic Agricultural System. 2012. Scoping Report. Barotse Floodplain, Zambia. Penang, Malaysia: WorldFish Center.

Colfer, Carol J. P., E Andriamampandry, S. Asaha, E. Lyimo, E. Martini, J. L. Pfund, and J. Watts. 2011. "Participatory Action Research for Catalysing Adaptive Management: 
Analysis of a 'Fits and Starts' Process." Journal of Environmental Science and Engineering 5 (1):28-43.

Crane, P., and L. Richardson. 2000. The Reconnect Action Research Kit. Canberra, Australia: Australian Government, Department of Family and Community Services.

Diaw, M. C., T. Aseh, and R. Prabhu. 2009. In Search of Common Ground: Adaptive Collaborative Management in Cameroon. Bogor, Indonesia: CIFOR.

Drucker, Peter F., and Joseph Maciariello. 2008. Management. Revised. Harper Collins E-book. https://www.academia.edu/35149943/Peter_F_Drucker_Management_Rev_Ed.

Eigenbrode, Sanford D., Michael O Rourke, J D Wulfhorst, David M Althoff, Caren S Goldberg, Kaylani Merrill, Wayde Morse, et al. 2007. "Employing Philosophical Dialogue in Collaborative Science.” BioScience 57 (1):55-64.

Evans, K., S. J. Velare, R. P. Prieto, S. N. Rao, S. S Sertzen, Karina Dávila, P. Cronkleton, and W. De Jong. 2006. Field Guide to the Future: Four Ways for Communities to Think Ahead. Nairobi, Kenya: CIFOR, ASB, World Agroforestry Centre.

Evans, K., A. Larson, E. Mwangi, P. Cronkleton, T. Maravanyika, X. Hernandez, P. Muller, et al. 2014. Field Guide to Adaptive Collaborative Management and Improving Women's Participation. Bogor, Indonesia: CIFOR.

Foran, T., J.R.A. Butler, L. J. Williams, J. Wanjura, A. Hall, L. Carter, and P.S. Carberry. 2014. "Taking Complexity in Food Systems Seriously: An Interdisciplinary Analysis." World Development 61:85-101.

German, L.A., A.M. Tiani, A. Daoudi, T. Mutimukuru-Maravanyika, E. Chuma, C. Jum, N. Nemarundwe, E. Ontita, and G. Yitamben. 2012. The Application of Participatory Action Research to Climate Change Adaptation in Africa: A Reference Guide. Bogor: IDRC and CIFOR.

Gluck, Sherna B., and Patai Daphne. 1991. Women's Words: The Feminist Practice of Oral History. New York: Routledge.

Greenwood, Davydd, and Mark Levine. 1998. Introduction to Action Research: Social Research for Social Change. London: Sage.

Hammersley, Martyn, and Paul Artinson. 1995. Ethnography: Principles in Practice. New York: Routledge.

Hattori, R. A., and T. Lapidus. 2004. "Collaboration, Trust and Innovative Change." Journal of Change Management 4 (2): 97-104.

IUCN. 2003. "Barotse Floodplain Zambia: Local Economic Dependence on Wetland Resources; Integrating Wetland Economic Values into River Basin Management." Case Studies in Wetland Valuation 2: May 2003 (produced under the "Integrating Wetland Economic Values into River Basin Management project" as part of the Water and Nature Initiative of IUCN: The World Conservation Union).

Kazungu, M. 2014. Socio-Economic Determinants for Cooperation in the Barotse Floodplain Small-Scale Fishery Management System, Zambia. Bonn, Germany: Faculty of Agriculture, University of Bonn.

Kemmis, Stephen, and Robin McTaggart. 2007. "Participatory Action Research: Communicative Action and the Public Sphere." In Strategies of Qualitative Inquiry, edited by N. Denzin and Y. Lincoln, 271-330. Thousand Oaks, CA: Sage.

Mackenzie, John, Poh-Ling Tan, Suzanne Hoverman, and Claudia Baldwin. 2012. "The Value and Limitations of Participatory Action Research Methodology." Journal of Hydrology 474: 11-21.

Madzudzo, E., A. Mulanda, J. Nagoli, J. Lunda, and B. D. Ratner. 2013. A Governance Analysis of the Barotse Floodplain System, Zambia: Identifying Obstacles and Opportunities. Penang, Malaysia: WorldFish. 
Mandondo, A, R. Prabhu, and F. Matose. 2008. Coping amidst Chaos: Studies on Adaptive Collaborative Management from Zimbabwe. Bogor, Indonesia: CIFOR.

Maravanyika, T., and W. Kozanayi. 2006a. "Collaborative Work in Rural Landscapes. Learning from the Zimbabwean Experiences." ACMZim News, December.

Maravanyika, T., and W. Kozanayi. 2006b. "Reflecting on the ACM Experiment: A Synthesis of the Experiences from the Learning Centres in Zimbabwe." ACMZim News, February.

Mauthner, Natasha S., and Andrea Doucet. 2003. "Reflexive Accounts and Accounts of Reflexivity in Qualitative Data Analysis." Sociology 37:413-31.

Mutimukuru, T., and W. Kozanayi. 2005. "From Glory to Shambles: The Rise and Fall of the Romwe Initiative," In ACMZim News: Keeping the Momentum: Sustaining Projects/ Processes When Outside Support Has Been Withdrawn, edited by Tendayi Mutimukuru and Witness Kozanayi. Harare, Zimbabwe: CIFOR.

Mutimukuru-Maravanyika, T. 2010. "Can We Learn Our Way to Sustainable Management? Adaptive Collaborative Management in Mafungautsi State Forest, Zimbabwe." Wageningen University and Research Centre. http://edepot.wur.nl /136242.

Mutimukuru-Maravanyika, T., and M. Apgar. 2014. Barotse Flood Plain RinD Capacity Assessment: Outcomes and Recommendations. Lusaka, Zambia: WorldFish.

Mutimukuru-Maravanyika, T., and S. Mwiya. 2014. SSA Team Planning Workshop for Mid- Year Review, 19-21 August 2014, Grand Palace Hotel in Lusaka, Zambia. Lusaka, Zambia: WorldFish Center.

Mutimukuru-Maravanyika, T., M. Apgar, E. Madzudzo, E. Mapedza, M. Kwashimbisa, C. Murungweni, S. Mwiya, and S. Cole. 2013. Proceedings of the Zambia AAS Annual Reflection Workshop at Senanga Safari Lodge, 4-7 November 2013, Lusaka, Zambia.

Mutimukuru-Maravanyika, T., C. Muyaule, A. Ward, N. Phiri, R. Paz-Ybarnegaray, and N. Chisonga. 2014. Proceedings of the Outcome Harvesting: TOC and RinD Capacity Assessment Workshop, Mongu, Zambia: WorldFish Center.

Mutimukuru-Maravanyika, T., D. Mills, C. Asare, and G. A. Ameyaw. 2016. "Enhancing Women's Participation in Decision-Making in Artisanal Fisheries in the Anlo Beach Fishing Community, Ghana." Water Resources and Rural Development 10:58-75.

Ojha, H., A. Hall, and R. Sulaiman. 2013. "Adaptive Collaborative Approaches in Natural Resource Governance: An Introduction.” In Adaptive Collaborative Approaches in Natural Resource Governance: Rethinking Participation, Learning and Innovation, edited by Hemant R. Ojha, Andy Hall and V. Rasheed Sulaiman, 1-19. London and New York: Earthscan.

Piggot-Irvine, E. 2012. "Creating Authentic Collaboration: A Central Feature of Effectiveness." In Action Research for Sustainable Development in a Turbulent World, edited by Ortrun Zuber-Skerritt, 89-107. Bingley, UK: Emerald Group Publishing Ltd.

Piggot-Irvine, E. 2015. "Collaboration, Innovation and Evaluation in Action Research. Life with Ortrum for a Better World." In Lifelong Action Learning and Research. A Tribute to the Life and Pioneering Work of Ortrun Zuber-Skerritt, edited by Judith Kearney and Maureen Todhunter, 47-64. Rotterdam/Boston/ Taipei: Sense Publishers.

Reynolds, Martin, and Sue Holwell. 2010. "Systems Approaches to Managing Change: A Practical Guide." In System Dynamics, edited by M. Reynolds and Sue Holwell, 25-85. London: Springer.

Schultz, C. A, and K. B. McIntyre. 2019. "Policy Design to Support Collaborative Landscape Restoration." In A New Era for Forest Landscape Management: Policy and Practice 
Insights from the Collaborative Forest Landscape Restoration Program, edited by W. B. Butler and C. A. Schultz, 195-211. London: Earthscan/ Routledge.

Smith, R, L. Syndall, and R Taylor. 2004. "Overcoming the PBRF Agenda: Fostering a Collaborative Partnership with Academic-Practitioners." Paper Presented at the New Zealand Association for Research in Education (NZARE) Conference, Wellington, New Zealand.

The WorldFish Center. 2007. Proceedings of the International Workshop on the Fisheries of the Zambezi Basin, 31 May-2 June 2004, Livingstone, Zambia. The WorldFish Center Conference Proceedings 75, 83 pp. Penang, Malaysia: The WorldFish Center.

Werkman, Renate, Jolanda Van Den Berg, Annemarie Van Paassen, and Bette Harms. 2011. "What Is Collaborative Landscape Research About?" In Knowledge in Action: The Search for Collaborative Research for Sustainable Landscape Development, edited by Annemarie van Paassen, Jolanda van den Berg, Eveliene Steingrover, Renate Werkman, and Pedroli Bas, 41-56. Wageningen, the Netherlands: Wageningen Academic Press.

Wollenberg, Eva, With D. Edmunds and L. Buck. 2000. Anticipating Change: Scenarios as a Tool for Adaptive Forest Management (a Guide). Bogor, Indonesia: CIFOR.

WorldFish Center. 2011. Aquatic Agricultural Systems. Project Flyer. Penang, Malaysia. 